\title{
PENINGKATAN NILAI TAMBAH USAHA TERNAK SAPI TERINTEGRASI DENGAN USAHA TANI PERKEBUNAN KELAPA DI DESA RAMBU-RAMBU KECAMATAN KOLONO TIMUR KABUPATEN KONAWE SELATAN
}

\author{
La Ode Arsad Sani ${ }^{1}$, La Ode Saidi' ${ }^{2}$, Syamsuddin $^{3}$, Firman Nasiu ${ }^{4}$, Astriana Napirah \\ 1,3,4,5 Jurusan Peternakan Fakultas Peternakan, Universitas Halu Oleo, Kendari \\ ${ }^{2}$ Jurusan Matematika FMIPA, Universitas Halu Oleo, Kendari \\ emailarsadni@yahoo.com
}

\begin{abstract}
ABSTRAK
Desa Rambu-Rambu merupakan salah satu desa di Kecamatan Kolono Timur yang masuk dalam daftar "Wilayah Kawasan Perdesaan Prioritas Nasional" di Kabupaten Konawe Selatan Provinsi Sulawesi Tenggara berdasarkan Lampiran Surat Direktur Riset dan Pengabdian Masyarakat Kemenristekdikti Nomor: 2276/E3/LL/2018 tertanggal 24 Juli 2018. Kecamatan Kolono Timur merupakan wilayah pesisir yang potensial untuk pengembangan komoditas perkebunan kelapa dan peternakan sapi sehingga dipilih menjadi lokasi penempatan KKN PPM yang didanai oleh Direktorat Riset dan Pengabdian Masyarakat Direktorat Jenderal Penguatan Riset dan Pengembangan Kemenristekdikti pada tahun 2019. Jarak tempuh lokasi KKN-PPM di Desa Rambu-Rambu Kecamatan Kolono Timur dengan Ibu Kota Kabupaten Konawe Selatan sekitar 92 km, dan berjarak sekitar 74 km dari Kampus Universitas Halu Oleo di Kendari. Mata pencaharian masyarakatnya selain beternak sapi adalah berkebun tanaman kelapa, jambu mete, kakao, cengkeh, kopi, lada, dan pala.

Perkebunan kelapa paling luas yaitu $323 \mathrm{Ha}$, sedangkan perkebunan dengan luas areal terkecil adalah tanaman cengkeh, yaitu 6 Ha. Kegiatan peternakan, khususnya ternak sapi dianggap sesuai dengan kondisi iklim setempat karena dukungan ketersediaan hijauan pakan ternak, walaupun masih mengandalkan sumber pakan dari hijauan rumput alami. Ternak sapi oleh masyarakat setempat telah diternakkan cukup lama, namun secara umum masih berjalan secara tradisional dan belum berorientasi bisnis sebagai sumber pendapatan utama karena pengetahuan dan keterampilan peternak masih terbatas. Beberapa kendala peternak mitra yang diidentifikasi adalah: (1) organisasi kelompok belum berjalan baik, (2) manajemen budidaya ternak sapi dan tanaman kelapa belum optimal, (3) feses ternak tidak diolah menjadi pupuk organik, (4) peternak mitra belum melakukan upaya penyediaan pakan berbasis hijauan unggul dan pakan hasil fermentasi. Oleh karena itu tujuan dilaksanakan pengabdian ini adalah memberikan pemahaman, pengetahuan dan keterampilan kepada masyarakat terkait peningkatan nilai tambah dari usaha ternak sapi terintegrasi tanaman kelapa. Metode yang digunakan berupa sosialisasi program (diskusi dan tanya jawab), mengadakan penyuluhan/pelatihan (ceramah, demonstrasi, kegiatan praktek), pendampingan (bimbingan teknis, monitoring dan evaluasi). Hasil dari program KKN PPM ini bahwa peternak telah memahami pentingnya wadah kelompok ternak, peternak lebih mengerti teknik membudidayakan ternak sapi terintegrasi tanaman kelapa, terampil membuat kandang ternak sapi, dan membuat pakan jerami fermentasi maupun dalam pengolahan pupuk organik berbasis feses sapi.
\end{abstract}

Kata Kunci : Limbah pertanian, pakan ternak, pupuk, perkebunan, ternak sapi. 


\begin{abstract}
Rambu-Rambu Village is one of the villages in Sub-district Kolono Timur which is included in the list of "Rural Areas of National Priority" in South Konawe Regency, Southeast Sulawesi Province based on the Appendix of the Director of Research and Community Service Ministry of Research and Technology Number: 2276/E3/LL/2018 dated 24 July 2018. Sub-district Kolono Timur is a potential coastal area for the development of coconut plantation and cattle breeding commodities so that it is chosen to be the location of KKN PPM placement funded by the Directorate of Research and Community Service Directorate General of Research Strengthening and Development Ministry of Research, Technology and Higher Education in 2019. Distance traveled in KKN- PPM in Rambu-Rambu Village, Sub-district Kolono Timur to the capital of South Konawe Regency is about $92 \mathrm{~km}$, and is about $74 \mathrm{~km}$ from the Halu Oleo University Campus in Kendari. The livelihoods of the people besides raising cattle are planting coconut, cashew nuts, cocoa, cloves, coffee, pepper and nutmeg. The most extensive plantation is coconut plantation, which is $323 \mathrm{Ha}$, while the plantation with the smallest area is clove, which is $6 \mathrm{Ha}$. Animal husbandry activities, especially cattle, are considered to be suitable with local climatic conditions due to the support of forage availability, although farmers still rely on feed sources from natural grasses. Cattle by local communities have been farmed for a long time, but in general, they still operate traditionally and are not yet business oriented as the main source of income because farmers' knowledge and skills are still limited. Some problems identified by the breeders are: (1) the group organization has not been running well, (2) the management of cattle and coconut cultivation is not yet optimal, (3) the livestock feces is not processed into organic fertilizer, (4) the partner breeders have not made efforts to provide superior forage-based and fermented feed. Therefore, the aim of this service community is to provide understanding, knowledge and skills to the community related to the increasing of additional value of the cattle business integrated with coconut plantation. The methods used are program socialization (discussion and question and answer), conducting counseling / training (lectures, demonstrations, practical activities), mentoring (technical guidance, monitoring and evaluation). The results of the PPM-KKN program are that the farmer better understands the importance of livestock group, the farmer better understands the techniques of raising cows integrated with coconut plantation, skilled in making cattle pens, skilled in making fermented straw feed and in the processing of cow manure-based organic fertilizer.
\end{abstract}

Keywords : Agricultural by-product, feed, fertilizer, plantations, cattle.

\title{
PENDAHULUAN
}

Kecamatan Kolono Timur merupakan satu-satunya kecamatan yang masuk dalam daftar "Wilayah Kawasan Perdesaan Prioritas Nasional” di Kabupaten Konawe Selatan Provinsi Sulawesi Tenggara berdasarkan Lampiran Surat Direktur Riset dan Pengabdian Masyarakat Kemenristekdikti Nomor: 2276/E3/LL/2018 tertanggal 24 Juli 2018. Kecamatan Kolono Timur merupakan wilayah pesisir yang potensial untuk pengembangan komoditas perkebunan kelapa dan peternakan sapi. Jarak tempuh lokasi penempatan KKN-PPM di Desa Rambu-Rambu Kecamatan Kolono Timur dengan Ibu Kota Kabupaten Konawe Selatan sekitar 92.7 km, dan berjarak sekitar 74 km dengan Kampus Universitas Halu Oleo di Kota Kendari. 
Tanaman perkebunan yang banyak diusahakan di Kecamatan Kolono Timur selain tanaman kelapa, yaitu jambu mete, kakao, cengkeh, kopi, lada, dan pala. Namun demikian tanaman perkebunan kelapa mempunyai luas tanam paling luas (323 Ha), kemudian tanaman jambu mete seluas 111 ha sedangkan tanaman perkebunan yang luasannya paling kecil adalah tanaman cengkeh yaitu 6 Ha. Diantara beberapa tanaman perkebunan tersebut terdapat 3 komoditas unggulan dengan status lahan produktif pada tahun 2016, yaitu tanaman kelapa 293 ha dengan tingkat produksi sebanyak 1.318 ton, jambu mete 91 ha dengan produksi 91 ton dan kakao 38 ha yang hanya menghasilkan sebanyak 38 ton (BPS Kab. Konawe Selatan, 2017).

Selain usaha perkebunan kelapa, kegiatan peternakan sapi dianggap sesuai dengan kondisi iklim di Desa Rambu-Rambu walaupun masih mengandalkan sumber pakan dari hijauan rumput alami karena semakin terbatasnya jumlah hijauan pakan ternak yang ada di areal perkebunan kelapa, khususnya di musim kemarau. Untuk itu diperlukan sumber-sumber pakan alternatif seperti pemanfaatan limbah hasil pertanian seperti jerami padi atau jagung, limbah pod buah kakao maupun penanaman bibit unggul hijauan pakan ternak seperti rumput gajah, rumput raja, setaria dan jenis tanaman hijauan lokal lainnya. Sementara menurut Heryanto et al. (2016) dan Imran et al. (2012) bahwa pemberian nutrisi yang bagus diiringi dengan strategi manajemen yang baik dapat meningkatkan produktivitas sapi Bali. Erlangga (2013), menegaskan bahwa pakan yang diberikan untuk sapi potong dibedakan menjadi dua macam, yaitu pakan hijauan dan pakan konsentrat. Sedangkan Sutrisno (2009), menyatakan bahwa pakan bagi ternak ruminansia tergantung dari penyediaan hijauan dengan jumlah cukup, berkualitas tinggi dan berkesinambungan sepanjang tahun. Rendahnya nilai gizi dan fluktuasi produksi hijauan pakan sepanjang tahun merupakan masalah penyediaan pakan di Indonesia sampai saat ini.

Ternak sapi oleh masyarakat setempat telah diternakkan cukup lama, namun kegiatan ini secara umum masih berjalan secara tradisional dan belum diusahakan secara baik yang berorientasi bisnis sebagai sumber pendapatan utama karena keterbatasan pengetahuan dan keterampilan yang dimiliki. Masyarakat umumnya lebih tertarik memelihara ternak sapi untuk dijadikan usaha sambilan yang dapat dimanfaatkan sebagai tabungan keluarga dan sewaktu-waktu dapat dijual agar memperoleh uang tunai untuk kebutuhan rumah tangga setelah mereka menyelesaikan pekerjaan utama sebagai petani kelapa.

Oleh karena itu, upaya penting yang perlu dilakukan adalah peningkatan pengetahuan dan keterampilan petani/peternak seperti pelatihan dan introduksi teknologi tepat guna untuk meningkatkan nilai tambah usaha peternakan sapi melalui pendekatan agrokompleks secara terintegrasi (bertani dan 
berternak). Melakukan diversifikasi jenis usaha dengan menambah keragaman dan produktivitas usahataninya yang diterapkan melalui metode kombinasi pengusahaan tanaman pertanian dengan usaha peternakan sapi yang saling menguntungkan.

\section{METODE}

Kegiatan pengabdian dosen yang melibatkan mahasiswa Fakultas Peternakan Universitas Halu Oleo melalui program KKN-PPM yang dilaksanakan melalui beberapa tahap yaitu survey dan identifikasi lokasi kegiatan, penempatan mahasiswa $\mathrm{KKN}$, rekrutmen mahasiswa, pembekalan mahasiswa dan pelaksanaan program KKN-PPM di Desa Rambu-Rambu Kecamatan Kolono Timur Kabupaten Konawe Selatan.

Metode yang ditawarkan untuk meningkatkan produktivitas usahatani dan usaha ternak sapi di Desa Rambu-Rambu Kecamatan Kolono Timur adalah melaksanakan sosialisasi program (diskusi dan tanya jawab), mengadakan penyuluhan/pelatihan (ceramah, demonstrasi, kegiatan praktek), pendampingan (bimbingan teknis, monitoring dan evaluasi). Dari sisi teknologi proses penyampaian materi penyuluhan dan pelatihan akan memanfaatkan perangkat-perangkat teknologi seperti komputer, LCD, kamera dengan pendampingan bersama antara mahasiswa beserta Dosen Pembimbing Lapangan (DPL). Introduksi teknologi tepat guna terhadap peningkatan nilai usaha peternakan sapi akan memanfaatkan teknologi mekanisasi Copper (alat pencacah pakan hijauan) dan Appo (mesin pengolah pupuk organik), teknologi probiotik sebagai agen pertumbuhan dan fermentasi.

Sebelum mahasiswa diberangkatkan ke lokasi KKN, maka terlebih dahulu mahasiswa dibekali dengan pengetahuan praktis melaksanakan sosialisasi program, melakukan pendampingan, proses penyuluhan, pelatihan, atau bimbingan teknis yang bersesuaian dengan proses pendampingan dan tema program KKN-PPM yang telah direncanakan sebelumnya.

\section{PEMBAHASAN}

Pelaksanaan kegiatan pengabdian skim KKN-PPM kerjasama tim dosen Universitas Halu Oleo dan Kemenristekdikti di Desa Rambu-Rambu Kecamatan Kolono Timur Kabupaten Konawe Selatan dilaksanakan selama 1 (satu) bulan, sejak tanggal 13 Juli 2019 sampai 14 Agustus 2019. Bentuk kegiatan KKN-PPM utama oleh mahasiswa diaplikasikan dalam bidang kegiatan pertanian dan peternakan. Kegiatan di bidang pertanian diantaranya: 1) pembuatan kebun percontohan tanaman hijauan makanan ternak rumput odot dan rumput gajah, 2) Pembuatan briket arang dari tempurung kelapa sebagai sumber 
bahan bakar skala rumah tangga. Sedangkan kegiatan bidang peternakan meliputi: 1) penyuluhan, pelatihan pembuatan pupuk kompos berbasis feses ternak sapi 2) pembuatan silase rumput gajah sebagai pakan ternak sapi, 3) pendampingan dan praktek pembuatan kandang sapi percontohan.

\section{Program Kerja Bidang Pertanian}

a) Pengadaan Kebun Percontohan Tanaman Hijauan Pakan Ternak

Sistem pemeliharaan ternak sapi di Desa Rambu-rambu bersifat tradisional sehingga jenis pakan ternak yang digunakan umumnya hanya memanfaatkan rumput alami yang tumbuh liar. Sementara masih terdapat lahan kosong yang belum dimanfaatkan untuk media tanam Hijauan Pakan Ternak (HPT). Hijauan pakan ternak yang tumbuh secara liar tidak dapat dikontrol ketersediaannya karena keberadaannya masih tergantung dengan kondisi alam. Oleh karena itu dilakukan pengadaan kebun percontohan budidaya HPT yang berkualitas seperti tanaman hijauan pakan ternak rumput odot dan rumput gajah untuk menunjang kebutuhan dan ketersediaan pakan ternak secara berkelanjutan. Pembuatan kebun percontohan dan penanaman HPT dilakukan pada bidang tanah potensial berupa lahan kosong agar dapat meningkatkan nilai dan manfaat serta fungsi dari HPT tersebut. Hijauan pakan ternak yang ditanam berupa rumput odot dan rumput gajah seperti terlihat pada Gambar 1.
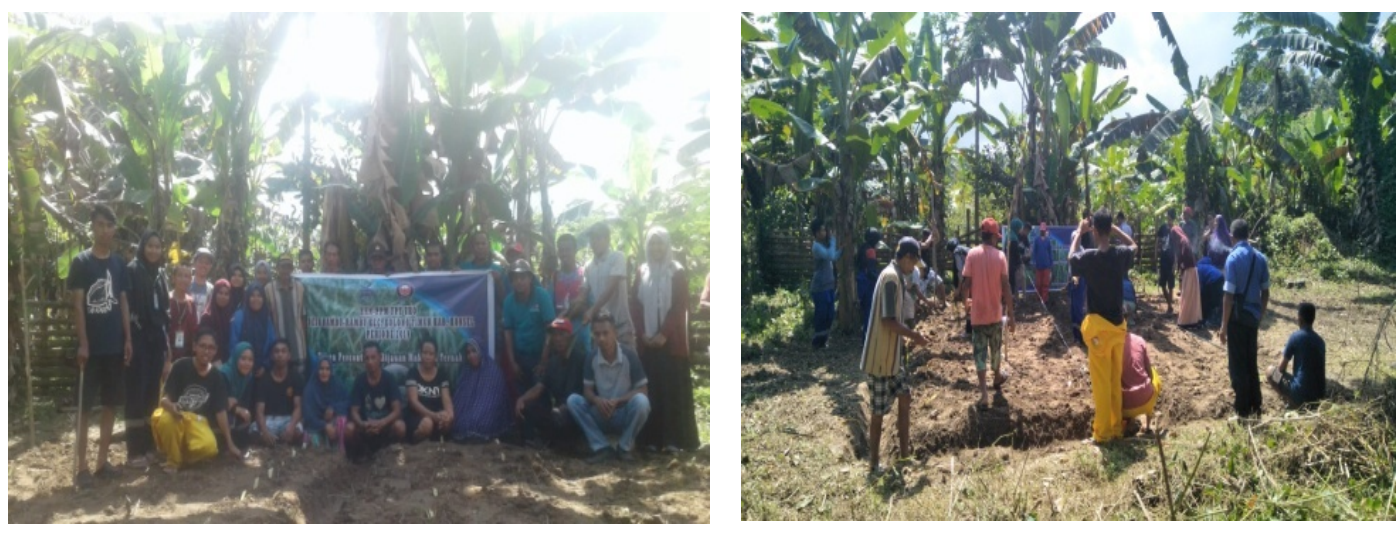

Gambar 1. Penanaman Hijauan Pakan Ternak Rumput Odot dan Rumput Gajah

b) Penyuluhan dan Pembuatan Briket Arang Tempurung Kelapa

Briket merupakan sebuah blok bahan yang bisa dibakar untuk dijadikan bahan bakar. Briket dari tempurung kelapa ini menjadi bahan bakar alternatif yang memiliki banyak keuntungan jika menggunakannya. Briket ini sangat membantu dalam hal memasak dan berbagai kebutuhan lainnya, 
briket ini menjadi bahan bakar alternatif yang cukup hemat dan bisa menjadi pilihan masyarakat. Briket ini memiliki banyak keunggulan karena mampu menghasilkan energi panas tinggi serta bisa tahan lama, membuat bahan bakar satu pilihan tepat untuk menghemat pengeluaran. Fariadhie (2009), menyatakan bahwa briket merupakan bahan bakar padat yang dapat digunakan sebagai bahan bakar alternatif pengganti minyak tanah. Jenis-jenis briket berdasarkan bahan baku penyusunanya terdiri dari briket batubara.

Bahan-bahan yang digunakan untuk pembuatan briket tempurung kelapa yaitu tempurung kelapa, drum besi, minyak tanah, dan korek. Proses pembuatan briket tempurung kelapa yaitu menyediakan drum besi kemudian disimpan tempurung kelapa setengah dari ruang drum besi kemudian dibakar setelah menyala diletakan lagi tempurung kelapa sampai penuh dan menunggu sampai keluar asap, dibiarkan sampai tempurung kelapa sampai jadi arang. Setelah jadi arang dikeluarkan dan didinginkan dengan cara dijemur lalu dibungkus.

Pembuatan pakan pellet ini diharapkan dapat memberikan pengetahuan baru bagi masyarakat setempat baik cara pembuatan briket arang tempurung kelapa. Proses pembuatan briket tempurung kelapa di lokasi KKN-PPM di Desa Rambu-Rambu Kecamatan Kolono Timur Kabupaten Konawe Selatan dapat dilihat pada Gambar 2.
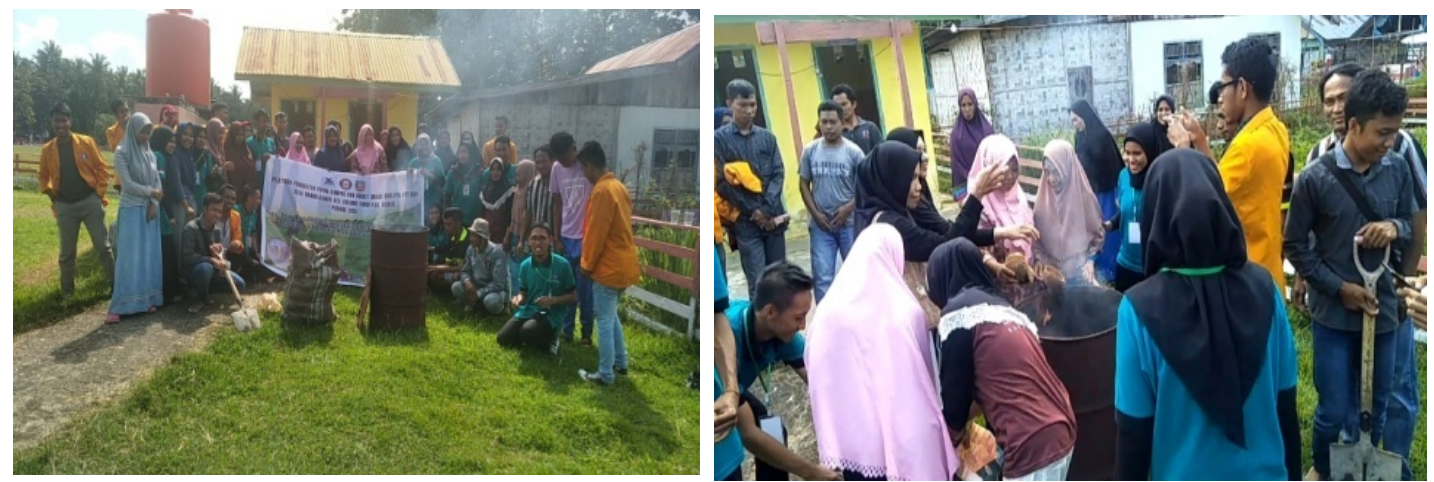

Gambar 2. Pembuatan Briket Arang Tempurung Kelapa

\section{Program Kerja Bidang Peternakan}

a) Pembuatan Pupuk Kompos Berbasis Fases Ternak Sapi

Pupuk organik umumnya dihasilkan dari proses pengomposan sehingga sering disebut juga dengan kompos. Pengomposan merupakan proses dimana bahan-bahan organik mengalami penguraian secara biologis, khususnya oleh mikroba yang dapat memanfaatkan bahan organik sebagai sumber energi. Kompos adalah hasil penguraian tidak lengkap dan dapat dipercepat secara 
artifisial oleh populasi berbagai macam mikroba dalam kondisi lingkungan yang hangat, lembab, dan dalam kondisi anaerob. Menurut Firman (2016), bahwa pupuk organik merupakan pupuk yang berasal dari tumbuhan mati, kotoran hewan dan/atau bagian hewan atau limbah organik lainnya yang telah melalui proses rekayasa, berbentuk padat atau cair, dapat diperkaya dengan bahan mineral atau mikroba yang bermanfaat untuk meningkatkan kandungan hara dan bahan organik tanah, serta memperbaiki sifat fisik, kimia dan biologi tanah.

Bahan dasar dari pembuatan pupuk kompos pada kegiatan ini yaitu feses sapi, daun gamal, daun jati, sekam kayu, EM4 (effective mikroorganisme), larutan gula pasir, dan dedak padi. EM4 sebagai aktivator yang berfungsi menguraikan sisa organik yang telah mati menjadi unsur-unsur yang dikembalikan ke dalam tanah $\left(\mathrm{N}, \mathrm{P}, \mathrm{K}, \mathrm{Ca}, \mathrm{Mg}\right.$, dll) dan atmosfer $\left(\mathrm{CH}_{4}\right.$ atau $\left.\mathrm{CO}_{2}\right)$ sebagai unsur hara yang dapat digunakan kembali untuk tanaman. Metode yang digunakan dalam pembuatan pupuk kompos yaitu dengan menggunakan bahan terpal dengan ukuran $4 \times 4 \mathrm{~m}$. Produser pembuatan pupuk kompos/organik dapat dilihat pada Gambar 2. Adapun bahan yang dibutuhkan dalam pembuatan pupuk kompos yaitu: feses sapi, daun gamal, dedak padi, daun jati, sekam kayu, gula pasir, probiotik EM4, dan air secukupnya.

Prosedur cara pembuatan pupuk kompos :

1. Bahan pupuk terdiri dari feses sapi, tanah, daun gamal, daun jati, sekam, dedak padi dicampur hingga merata.

2. Air yang dicampur EM4 sedikit demi sedikit disiram dalam tumpukan feses sapi hingga merata sampai membentuk adonan dengan kadar air $\pm 40 \%$.

3. Adonan bahan pupuk yang telah disatukan selanjutnya dibungkus menggunakan terpal hingga tertutup rapat dan disimpan \pm 14 hari dalam kondisi anaerob. Proses fermentasi akan berlangsung cepat sehingga suhu kompos meningkat hingga $30-40^{\circ} \mathrm{C}$.
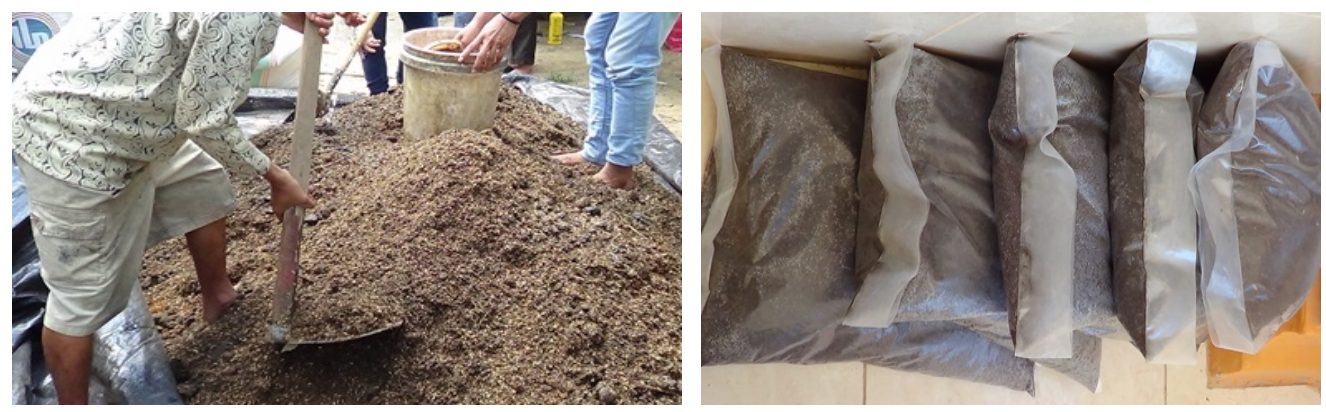

Gambar 3. Pembuatan Pupuk Kompos 
b) Penyuluhan dan Pelatihan Pembuatan Pakan Fermentasi

Silase merupakan pakan yang telah diawetkan yang diproses dari bahan baku berupa tanaman hijauan, limbah pertanian serta bahan pakan alami lainnya, dengan jumlah kadar air tertentu, kemudian dimasukkan dalam tempat tertutup rapat kedap udara yang biasa disebut dengan silo selama tiga minggu. Menurut Wiwik $d k k$. (2018) bahwa silase merupakan upaya pengawetan hijauan segar dengan metode fermentasi dan dalam kondisi anaerob dengan tujuan untuk menambah daya simpan hijauan sehingga dapat dimanfaatkan dalam waktu lama terutama pada saat musim kemarau.

Bahan yang digunakan dalam proses pembuatan silase yaitu rumput odot, EM-4 (sumber mikroba), gula pasir, air. Dedak (sebagai sumber energi bagi mikroba), wadah (sebagai tempat pengaktifan mikroba), kantong plastik ukuran 100 x $100 \mathrm{~cm}$ berwarna hitam dan lakban. Hal yang harus diperhatikan dalam pembuatan silase rumput odot yaitu:

1. Rumput odot usia lebih dari 60 hari atau sebagian daun sudah mulai ada yang berwarna kecoklatan atau kering, sebab pada saat itu nilai nutrien optimal. Kadar air hijauan pakan berkisar 58-72\%, kadar air diatas 72\% akan melarutkan beberapa macam nutrien dan kadar air kurang dari 58\% akan mengalami kesukaran dalam proses pemadatan.

2. Hijauan pakan dicacah atau dipotong-potong pendek 3-5 cm agar mempermudah pemadatan dan penanganan selanjutnya.

3. Penutupan silo harus rapat agar kedap udara.

Langkah untuk membuat silase yaitu:

- Bahan silase dipotong-potong dengan ukuran sekitar 3-5 cm, jika odot masih banyak mengandung air bisa ditambahkan bahan kering seperti sekam kayu.

- Bahan silase diaduk hingga menjadi satu dan campuran secara merata, lalu dimasukkan kedalam silo/kantong plastik dan dipadatkan untuk memaksimalkan proses silase.

- Kemudian didiamkan/diinkubasi selama 21 sampai 30 hari, ditutup rapat secara anaerob dan tidak ada lubang udara.

- Proses silase/fermentasi berlangsung sekitar 21 hari dan apabila proses berjalan baik, ditandai dengan tidak adanya jamur dan baunya asam, agak manis maka penyimpanan dapat diteruskan sampai saat dibutuhkan. 

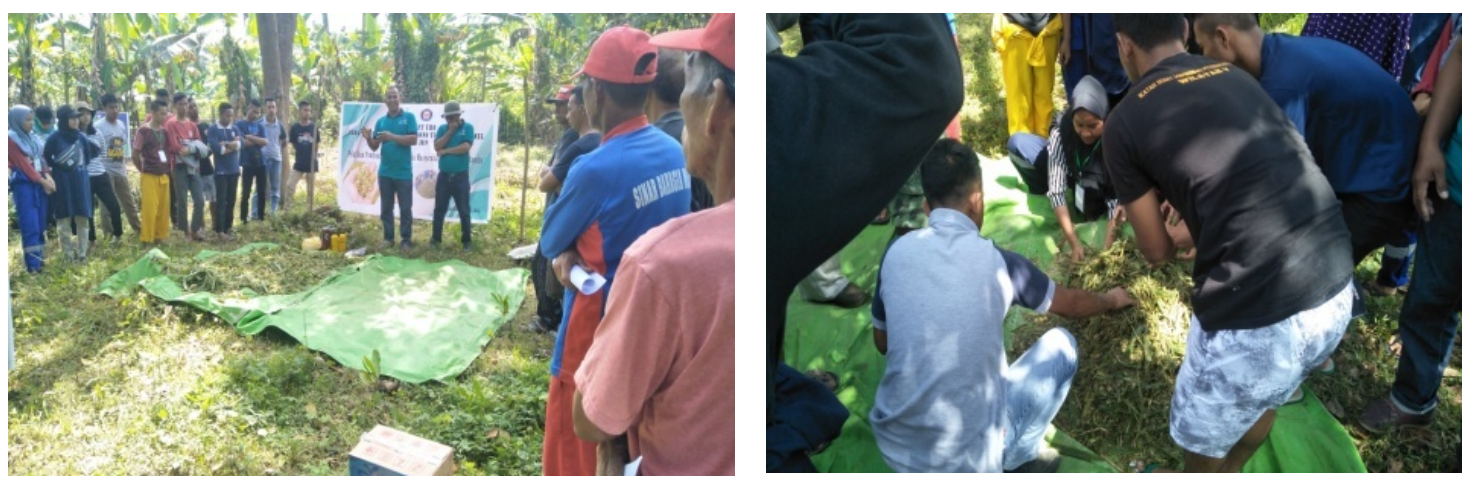

Gambar 4. Pembuatan Pakan Fermentasi Rumput Odot

c). Penyuluhan dan Pembuatan Kandang Sapi Percontohan

Pemeliharaan ternak sapi oleh masyarakat setempat masih bersifat tradisional. Maka dari itu diperlukan langkah khusus untuk mengatasi hal tersebut. Manajemen pemeliharaan yang baik perlu diperhatikan untuk memperoleh produksi yang lebih optimal. Namun manajemen yang baik tentu akan mempengaruhi pola pemeliharaan ternak yang dipelihara. Salah satu manajemen yang perlu diterapkan untuk menghasilkan produksi yang lebih optimal adalah pemeliharaan sapi dengan menggunakan kandang intensif. Tatalaksana perkandangan merupakan salah satu faktor produksi yang belum mendapat perhatian dalam usaha peternakan sapi potong khususnya peternakan rakyat. Konstruksi kandang belum sesuai dengan persyaratan teknis akan menganggu produktivitas ternak kurang efisien dalam penggunaan tenaga kerja dan berdampak terhadap lingkungan sekitarnya (Rasyid dan Hartati, 2007).

Kandang sapi yang baik dan efisien menjadi salah satu kunci sukses dalam pemeliharaan ternak sapi potong. Kandang mempunyai keuntungan yaitu dapat mempercepat perkembangan ternak, meningkatkan pendapatan peternak melalui penggunaan kotoran ternak menjadi pupuk, melindungi ternak dari perubahan cuaca, mencegah dan melindungi ternak dari penyakit dan menjaga keamanan ternak dari serangan predator atau kehilangan. Oleh karena itu, perlu adanya perkenalan terhadap masyarakat tentang contoh kandang yang sesuai untuk pemeliharaan sapi yang baik. Ada beberapa hal yang kita harus diketahui agar tidak salah dalam merancang dan membuat kandang sapi yang baik. Fungsi dari kandang yaitu melindungi ternak dari perubahan cuaca atau iklim yang ekstrem (panas hujan dan angin), mencegah dan melindungi ternak dari penyakit, menjaga keamanan ternak dari pencurian, memudahkan pengelolaan ternak dalam proses produksi 
seperti pemberian pakan, minum dan perkawinan serta meningkatkan efesiensi penggunaan tenaga kerja.

Penyuluhan dan pembuatan kandang sapi diharapkan dapat berdampak pada peningkatan pengetahuan peternak akan cara pembuatan kandang sapi yang ideal dan manfaat pembuatannya. Demplot kandang percontohan di lokasi KKN-PPM di Desa Rambu-Rambu Kecamatan Kolono Timur Kabupaten Konawe Selatan dapat dilihat pada Gambar 5.
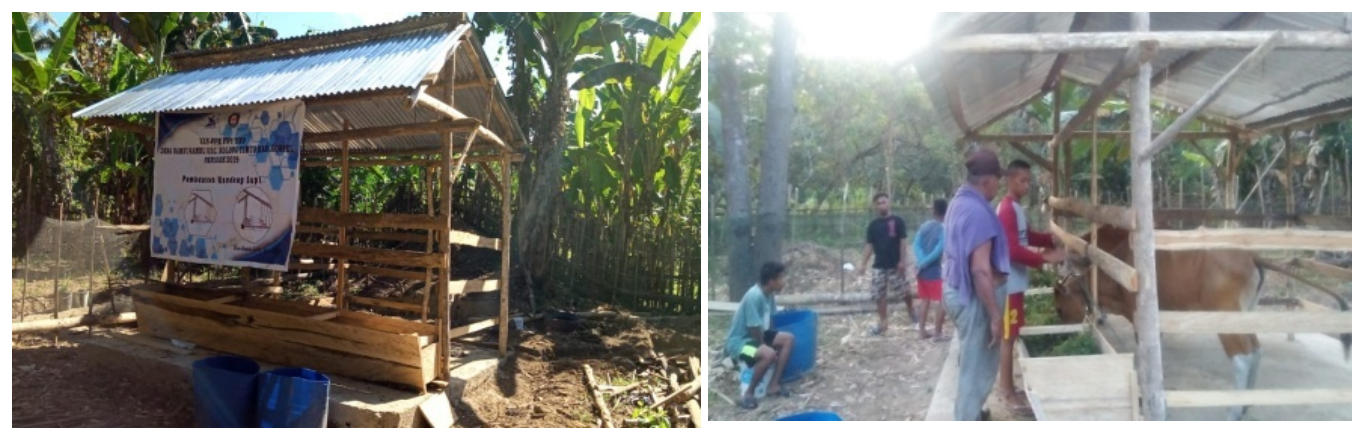

Gambar 5. Pembuatan Kandang Sapi Percontohan

\section{SIMPULAN}

Hasil yang telah dicapai pada kegiatan ini, yaitu adanya peningkatan pengetahuan dan pemahaman kelompok tani-ternak tentang teknik budidaya ternak sapi dalam kawasan perkebunan kelapa, pemanfaatan hijauan pakan ternak berupa rumput odot dan rumput gajah, peningkatan pengetahuan peternak tentang cara pembuatan kandang sapi yang ideal, cara pemanfaatan limbah feses ternak menjadi pupuk kompos dan introduksi pupuk kompos pada tanaman pertanian, rumput odot dan rumput gajah yang diusahakan secara bersama-sama dengan ternak sapi potong, serta cara pembuatan pakan fermentasi rumput odot. Selain itu, terjadi peningkatan pengetahuan peternak tentang pembuatan briket arang tempurung kelapa yang dapat dijual pada rumah-rumah makan di Kota Kendari untuk menambah penghasilan keluarga peternak.

\section{UCAPAN TERIMA KASIH}

Kami mengucapkan terima kasih dan penghargaan tinggi kepada Direktorat Riset dan Pengabdian Masyarakat Direktorat Jenderal Penguatan Riset dan Pengembangan Kementerian Riset, Teknologi, dan Pendidikan Tinggi atas dukungan dana yang diberikan sehingga kegiatan pengabdian dosen yang melibatkan mahasiswa dalam bentuk program pengabdian Kuliah Kerja Nyata Pemberdayaan Pembelajaran Masyarakat (KKN PPM) tahun pelaksanaan 2019. 


\section{DAFTAR PUSTAKA}

Erlangga, E. 2013. Meningkatkan Bobot Sapi Potong dengan Pakan Racikan Sendiri. Pustaka Argo Mandiri. Pamulang.

Firman, L. S. 2016. Kaji Terap Teknologi Komposting Untuk Penanganan Limbah Ternak Sapi Potong. Peneliti Pusat Teknologi Lingkungan. Badan Pengkajian dan Penerapan Teknologi.

Heryanto K, Maaruf, S.S, Malalantang., Waani M.R. 2006. Pengaruh Pemberian Rumput Gajah (Pennisetum Purpupoides) dan Tebon Jagung Terhadap Performans Sapi Peranakan Ongole (Po) Betina. Jurnal Zootek Vol. $36 . \quad$ No.1:123-130.

Imran, Budhi, S.P.S., Ngadiyono, N., Dahlanuddin. 2012. Pertumbuhan Pedet Sapi Bali Lepas Sapih yang Diberi Rumput Lapang dan Disuplementasi Daun Turi (Sesbania gransiflora). Agrinimal J Ilmu Ternak dan Tanaman. Vol.2 No.2:55-60.

Jeni Fariadhie. 2009. Perbandingan Briket Tempurung Kelapa dengan Ampas Tebu, Jerami dan Batu Bara. Program Studi Teknik Mesin Fakultas Teknik Universitas Sultan Fatah.

Rasyid, A. dan Hartati. 2007. Petunjuk Teknis Perkandangan Sapi Potong. Pusat Penelitian dan Pengembangan Peternakan. Badan Penelitian dan Pengembangan Pertanian Departemen Pertanian.

Sutrisno, C.I. 2009. Pemanfaatan Sumber Daya Pakan Lokal Terbarui. Seminar Nasional Kebangkitan Peternakan. Program Magister Ilmu Ternak Program Pascasarjana Universitas Diponegoro. Semarang.

Wiwik, S.W, Mashudi, dan Artharini, I. 2018. Kualitas Silase Rumput Odot (Pennisetum purpureum cv.Mott) dengan Penambahan Lactobacillus plantarum dan Molasses Pada Waktu Inkubasi Yang Berbeda. Jurnal Nutrisi Ternak Tropis Vol. 1 No. 1 pp 45-53. 